\title{
Aphanizomenon gracile increases in width in the presence of Daphnia. A defence mechanism against grazing?
}

\author{
Slawek CERBIN, ${ }^{*}$ Łukasz WEJNEROWSKI, Marcin DZIUBA \\ Department of Hydrobiology, Adam Mickiewicz University, Umultowska 89, 61-614 Poznań, Poland \\ *Corresponding author: cerbins@amu.edu.pl
}

\begin{abstract}
Filamentous cyanobacteria are frequently consumed by grazers like Daphnia, which can break filaments and make them more readily available to filter-feeders. However, various defence mechanisms against grazing have also been observed in cyanobacteria. Data concerning changes in the morphology of filamentous algae, especially their width in the presence of a grazer, are scarce. Field studies of filament morphology of cyanobacteria relate their changes to nutrient availability and temperature. Moreover, filament morphology displays significant differences in filament length and width among seasons. We hypothesised that the morphological changes in filament observed in the field - especially their width - could be a defence mechanism that is induced by the presence of a grazer, such as Daphnia. Thus, two experiments were conducted in order to test the influence of Daphnia (direct grazing and infochemicals together in the first experiment) and the chemicals it released (grazing excluded, only chemicals present in the second experiment) on Aphanizomenon gracile's morphology, in controlled laboratory conditions. Aphanizomenon filaments became significantly shorter and thicker in both experiments. However, Daphnia's grazing combined with excreted chemicals had stronger effect than chemicals alone. To our knowledge, this is the first report describing the shortening and thickening of filaments in the presence of Daphnia infochemicals. It seems that the Aphanizomenon filaments in the presence of Daphnia switch their growing mode and invest more heavily in width than length. Our results support the hypothesis that Daphnia is at least partly responsible for the changes in filament width observed in the field. This could be a strategy that helps Aphanizomenon to withstand grazer's pressure during early stages of a bloom.
\end{abstract}

Key words: filamentous cyanobacteria, grazing, induced defence, mechanical interference, infochemicals.

Received: March 2013. Accepted: May 2013.

\section{INTRODUCTION}

The necessity to minimise the risk of predation and the ability to defend against predators are believed to be driving forces in the evolutionary histories of organisms at lower trophic levels (Tollrian, 1995). Thus, many organisms have evolved a variety of defence mechanisms. Van Donk et al. (2011) reviewed various induced defences in phytoplankton against grazing by herbivorous zooplankton. They distinguished three mechanisms of defence: i) morphological, such as forming colonies and developing spines (Hessen and Van Donk, 1993), bristles (Luo et al., 2006) or thicker cell walls (Pondaven et al., 2007); ii) chemical, such as toxic metabolites (Jang et al., 2003); and iii) changes in life history, such as vertical migration (Latta et al., 2009) or cyst formation (Toth et al., 2004). A good example of these defences occurs in phytoplankton with flexible morphologies (Lürling and Van Donk, 1996) or colony sizes (Jakobsen and Tang, 2002). For example, the green alga Scenedesmus sp., in the presence of a grazer such as Daphnia, produces many-celled cenobia that prevent it from entering the filtering chamber of a filter feeder (Lürling and Van Donk, 1996).

Various defence mechanisms against grazing have also been observed in cyanobacteria. Cyanobacterial toxins are known to have adverse effects on Daphnia: Jang et al. (2003) observed the induction of toxin production in Microcystis aeruginosa in the presence of Daphnia. Moreover, Jang et al. (2007) demonstrated that grazing pressure and infochemicals that are released by grazers can induce toxin production and secretion in filamentous Planktothrix agardhii. There are many examples of the negative influence of cyanobacteria's morphology on Daphnia. Filamentous blue-green algae strongly disrupt food collection in daphnids, which are forced to clean their filtering apparatuses (Gliwicz and Siedlar, 1980; Burns, 1968).

However, filamentous cyanobacteria are frequently consumed and can support the growth of Daphnia; for example, at low food levels, the addition of non-toxic filamentous Aphanizomenon flexuosum improved the growth of Daphnia galeata (Kurmayer, 2001). Moreover, Von Elert et al. (2003) observed that the growth rate of $D$. galeata that were fed filamentous Anabaena variabilis enriched with sterols was nearly equal to the growth of daphnids that were fed Scenedesmus obliquus.

Data concerning changes in the morphology of fila- 
mentous algae, especially their width in the presence of a grazer, are scarce. Daphnia can break filaments and make them shorter, which may increase their availability to filter-feeders (Dawidowicz, 1990). Oberhaus et al. (2007) reported that $D$. pulicaria preferentially graze on filaments of $P$. rubescens that are shorter than $100 \mu \mathrm{m}$. Conversely, Chen et al. (2011) reported no preference in Daphnia for shorter or longer filaments of Ulothrix. The length distribution of filaments in daphnids' guts was related to their length in lake water. Moreover, Nadin-Hurley and Duncan (1976) found that a limiting factor for ingestion was the width, rather than length, of a particle, and most of the very large particles that were found in the daphnid's gut were long, narrow, pliant filaments, such as those in Tribonema. Some Cyanobacteria can defend themselves by changing their filament morphology. Fijałkowska and Pajdak-Stós (1997) described the withdrawal of the Phormidium trichomes into their sheaths when they were disturbed by grazing ciliates. Moreover, Pajdak-Stós et al. (2001) reported that Phormidium autumnale produced an extracellular polysaccharide (EPS) envelope that was surrounded by filaments, thus protecting them from grazing by ciliates that could not penetrate the EPS mucilage. It has also been suggested that Aphanizomenon produces grass-like blades as an adaptation to avoid grazing by Daphnia (Lynch and Shapiro, 1981).

On the other hand, field studies of filament morphology relate their changes to nutrient availability and temperature, e.g. Planktothrix agardhii's filament morphology displayed significant differences in filament length and width among seasons, with the longest and widest occurring during summer and autumn (Pouličkova et al., 2004). A different pattern was reported by Kokociński et al. (2010), who observed the longest and widest trichomes during winter and spring. Laamanen et al. (2001) noticed that the same strain of Nodularia, when grown under different chemical or physical conditions, differed in its cell dimensions. Hašler and Pouličkova (2003) noted that the widest trichomes of $P$. agardhii coincided with the highest phosphorus (P) concentrations during their experiments. The trichome width was demonstrated to be the significant feature that differentiated different populations of $P$. agardhii, while the length was positively correlated with nutrient availability and temperature (Gonzalez, 1981; Romo, 1994).

We hypothesised that the seasonal morphological changes in filaments, especially increase of their width, that were observed in the field could be a defence mechanism that is induced by the presence of a grazer, such as Daphnia. Therefore, we wanted to test how the physical disturbance that is caused by filtering influences filament morphology. However, if the widening of filaments is a defence response to grazing, it could also be induced by infochemicals that are secreted by a herbivore. To test our predictions and separate the mechanical interference from chemical induction, we conducted two experiments. The first experiment tested the influence of Daphnia that was physically present in the culture of filamentous Aphanizomenon gracile. In the second experiment, we cultured A. gracile with daphnids that were kept in cages to avoid direct contact with filaments to test the induction of morphological changes by chemicals alone. Even though filamentous algae are avoided by Daphnia, they are frequently a part of their diet. Daphnia can suppress cyanobacterial blooms at the initial stage. It is important to understand the role of morphological changes of filamentous cyanobacteria observed in the field for evaluating possibilities of suppressing their developement.

\section{METHODS}

\section{Experimental organisms}

The cyanobacterium Aphanizomenon gracile (Lemmermann, 1910) SAG 31.79 was obtained from the culture collection of algae (Sammlung von Algenkulturen SAG) at the University of Göttingen. The stock of Aphanizomenon was cultivated in a phytotron (Conviron, Winnipeg, Canada) at $20^{\circ} \mathrm{C}$ in a $2 \mathrm{~L}$ chemostat on Wilkins-Chalgren (WC) medium (Guillard and Lorenzen, 1972) at a light intensity of $17.5 \mu \mathrm{mol}$ quanta $\mathrm{m}^{-2} \mathrm{~s}^{-1}$ for a cycle of $16 \mathrm{~h}$ darkness and $8 \mathrm{~h}$ light. The photosynthetically active radiation (PAR) intensity was measured using a light meter (LI-192 quantum sensor; LI-COR Biosciences, Lincoln, NE, USA).

A laboratory clone of Daphnia magna (Straus, 1820) was used in this study as a grazer and infochemical producer. Daphnids were cultured in an incubator at $20^{\circ} \mathrm{C}$ in $1 \mathrm{~L}$ glass beakers that were filled with $0.45 \mu \mathrm{m}$ filtered lake water. We used the green alga Scenedesmus obliquus (Kützing, 1833), strain SAG 276-3a, as a food source for the daphnids. However, during the experiments, no Scenedesmus cells were present.

\section{Experimental design}

\section{Mechanical interference}

This experiment lasted 12 days and consisted of 3 treatments that were replicated 5 times: control with Aphanizomenon alone (control), Aphanizomenon grown with Daphnia present from the start of the experiment (D-12) and, additionally, a third treatment in which Daphnia was added after 6 days of the experiment (D-6). All daphnids were able to graze on Aphanizomenon. Daphnids were replaced every second day with new individuals of a similar size. All of the daphnids were mature, and their sizes ranged from 3 to $4 \mathrm{~mm}$. Newborns, if present, were removed from the experimental vials as soon as they appeared. The experiment was performed in vials that were 
filled with $20 \mathrm{~mL}$ of WC media, placed in an incubator at $20^{\circ} \mathrm{C}$ with PAR intensity of $44 \mu \mathrm{mol}$ quanta $\mathrm{m}^{-2} \mathrm{~s}^{-1}$ using a 16:8 h light-dark cycle. Each treatment was replicated five times, and one individual of Daphnia was assigned to each flask of D-12 and D-6 treatments. The concentration of cyanobacteria in the experimental vessels was $2.714 \times 10^{-6}$ filaments $/ \mathrm{mL}$, while their average length was $225.2 \mu \mathrm{m}( \pm 16.45 \mathrm{SD})$ at the beginning of the experiment.

During the experiment, $1 \mathrm{~mL}$ samples were taken at the beginning and at the end (12 days). In the treatment in which daphnids were added after 6 days, the samples were taken before the daphnids were put into the vials.

\section{Infochemicals}

In the second experiment - which was also held for 12 days - we tested the influence of Daphnia's infochemicals on the morphology of Aphanizomenon. We distinguished 3 treatments, similar to the first experiment: control with Aphanizomenon only (control), Aphanizomenon grown with grazer infochemicals present from the start of the experiment (D-12), and a third treatment in which grazer infochemicals were added after 6 days of the experiment (D-6). The daphnids were not able to graze on Aphanizomenon because they were placed in $10 \mathrm{~cm}^{3}$ Falcon tubes with a mesh mounted at the bottom (size 500 $\mu \mathrm{m})$. The cages were immersed in containers with Aphanizomenon. Each treatment was replicated five times, and three individuals of Daphnia were assigned to each container of D-12 and D-6 treatments. The daphnids that were used for this experiment were mature and their sizes ranged from 3 to $4 \mathrm{~mm}$. The daphnids in cages were replaced with new individuals of a similar size every second day. All newborns were removed from the experimental containers as soon as they appeared. The experiment was performed in containers with $50 \mathrm{~mL}$ of WC media, placed in an incubator at $20^{\circ} \mathrm{C}$, with a PAR intensity of $44 \mu \mathrm{mol}$ quanta $\mathrm{m}^{-2} \mathrm{~s}^{-1}$ using a 16:8 h light-dark cycle. All of the containers were gently stirred every day. The concentration of Aphanizomenon in the experimental containers was $4.524 \times 10^{-6}$ filaments $/ \mathrm{mL}$, while the average length of filaments was $145.9 \mu \mathrm{m}( \pm 20.2 \mathrm{SD})$ at the beginning of the experiment.

During the experiment, $1 \mathrm{~mL}$ samples were taken at the beginning, after 6 days and at the end (12 days). In the treatment with grazer infochemicals added, the samples were taken after 6 days, before the daphnids were caged.

\section{Procedural control}

Because there were cages immersed in an Aphanizomenon culture in the second experiment and they were shaken gently every day, a procedural control was employed to exclude the possibility that mechanical disturbance could influence the filaments' morphologies. The procedural control consisted of treatments with Aphanizomenon cultures without cages and with empty cages (i.e. no Daphnia). This experiment did not result in significant differences in filament length between the two treatments, either at the beginning or at the end of the experiment (ANOVA: $\mathrm{F}_{1,8}=1.09, \mathrm{P}=0.32 ; \mathrm{F}_{1,8}=1.13, \mathrm{P}=0.31$, respectively). This result proves that the presence of the cages in the experimental containers with Aphanizomenon cultures did not have any effect on the length of the trichomes. Moreover, in order to confirm that daphnids had significantly reduced mechanical contact with filaments, we also examined filtering apparatuses and guts of daphnids present in cages during the infochemical experiment. There were no clumps detected and only a few filaments in the guts. This number of filaments can be neglected comparing to almost 3 millions of filaments per $\mathrm{mL}$ present outside of the cage.

\section{Statistical analyses}

The lengths of 50 filaments were measured in each sample at $400 \times$ magnification, and a total of 250 measurements per treatment were made. Widths of 30 filaments were measured at a magnification of $400 \times$, and a total of 150 measurements per treatment were made. The measurements from each replicate were averaged, and the resulting means were used for statistical analyses (i.e. 15 lengths and 15 widths). The statistical analyses were performed with STATISTICA 7.1. The lengths and widths of the Aphanizomenon filaments were compared between the different treatments separately for the beginning and end of the experiment using one-way ANOVA. If the ANOVAs detected overall significant differences, Tukey's post-hoc tests were run for pair-wise comparisons. The data were not normally distributed; however, ANOVAs are quite robust to non-normality (Underwood, 1997). The homogeneity of variance in all of the data was tested with Levene's test, and all of the data met this assumption.

\section{RESULTS}

\section{Mechanical interference}

The experiment began with filaments that did not differ significantly from one another, both in length and width, in any of the treatments (ANOVA: $\mathrm{F}_{2,12=} 3.518$, $\mathrm{P}=0.07 ; \mathrm{F}_{2,12}=0.18, \mathrm{P}=0.83$, respectively). However, Daphnia grazing had significant effects on the length of Aphanizomenon filaments at the end of the experiment

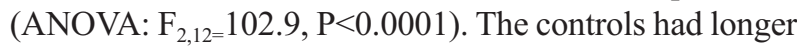
filaments than D-6 and D-12 (Tukey HSD test: $\mathrm{P}=0.0002$; $\mathrm{P}=0.0001$, respectively) (Fig. 1A). Moreover, the filaments in the D-6 treatment were longer than those in the D-12 treatment [Tukey honestly significant difference (HSD) test: $\mathrm{P}=0.0002]$.

Daphnia grazing also affected the width of the filaments 
(ANOVA: $\mathrm{F}_{2,12}=116.4, \mathrm{P}<0.0001$ ). The filaments in the $\mathrm{D}$ 12 treatment were thicker than those in the control and D-6 (Tukey HSD test: $\mathrm{P}=0.0001 ; \mathrm{P}=0.0001$, respectively), but no differences were observed between the control and D-6 treatments (Tukey HSD test: $\mathrm{P}=0.97$ ) (Fig. 1B).

\section{Infochemicals}

All of the filaments were of similar length and width at the beginning of the experiment that tested the influence of grazers' infochemicals on Aphanizomenon (ANOVA: $\mathrm{F}_{2,12}=1.7, \mathrm{P}=0.22 ; \mathrm{F}_{2,12}=0.08, \mathrm{P}=0.92$, respectively). However, at the end of the experiment, significant differences were observed in the length of filaments (ANOVA: $\mathrm{F}_{2,12} 8.1, \mathrm{P}=0.006$ ). The Aphanizomenon in the control had longer filaments than D-6 and D-12 (Tukey HSD test: $\mathrm{P}=0.006 ; \mathrm{P}=0.02$, respectively) (Fig. 2A). However, no differences were noted between D-6 and D-12.

Significant differences were also observed for the width of filaments (ANOVA: $\mathrm{F}_{2,12=} 71.3, \mathrm{P}=0.00001$ ). The D-12 and D-6 treatments had thicker filaments than the control (Tukey HSD test: $\mathrm{P}=0.0001 ; \mathrm{P}=0.0006$, respec- tively). The filaments in D-12 were also thicker than those in D-6 (Tukey HSD test: $\mathrm{P}=0.0002$ ) (Fig. 2B).

\section{DISCUSSION}

Our results support the hypothesis that Daphnia is responsible for the changes in filament width. Aphanizomenon gracile changed its morphology significantly when exposed to Daphnia's grazing or infochemicals. To our knowledge, this is the first report describing the shortening and thickening of filaments in the presence of Daphnia infochemicals.

During the first experiment, in the treatment in which daphnids were able to graze on Aphanizomenon, we observed shorter filaments in the treatment than in the controls (Fig. 1A). This result was expected and is associated with the mechanical interference in the filtering apparatus of Daphnia, where longer filaments break as a result of increased postabdominal rejection movements (Gliwicz and Siedlar, 1980; Hartmann and Kunkel, 1991). Therefore, previously inedible filaments may be efficiently eaten because they are shorter (Dawidowicz, 1990). This

A

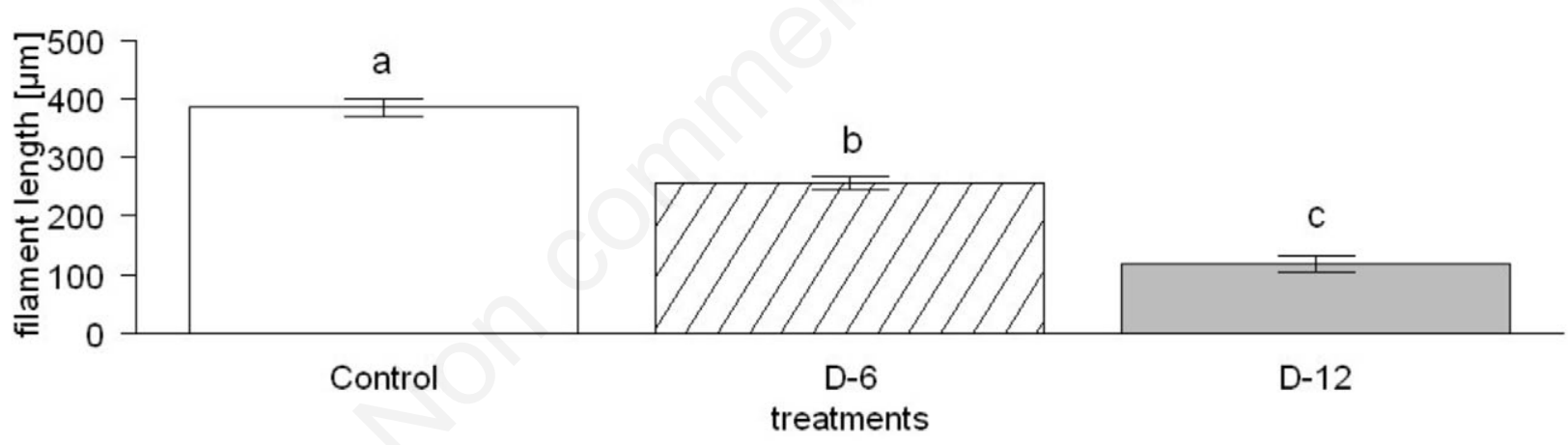

B

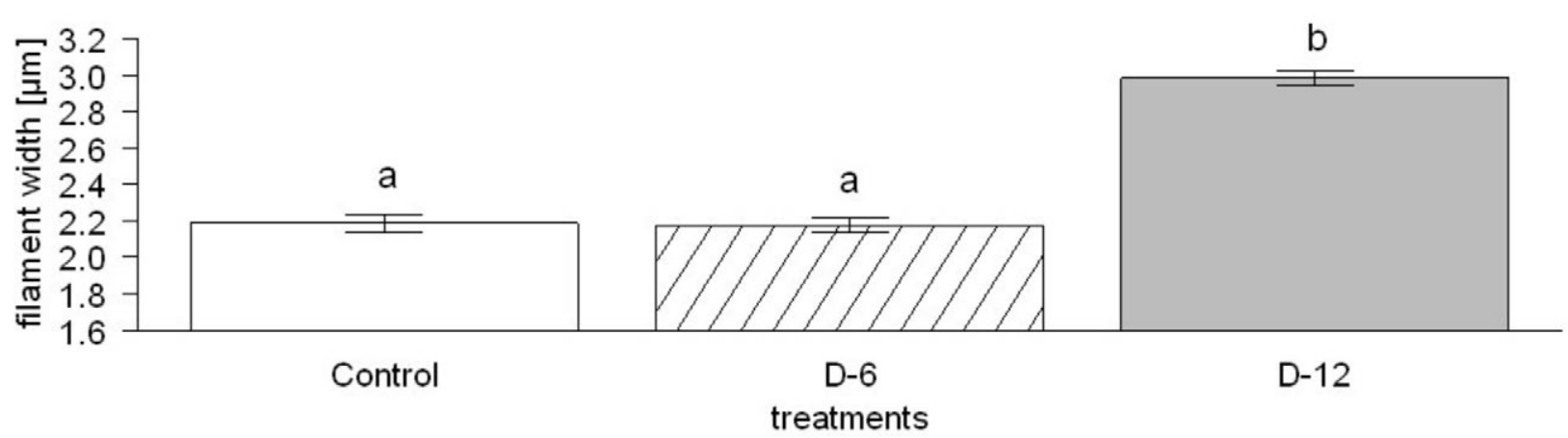

Fig. 1. Differences of Aphanizomenon's filaments in (A) length and (B) width at the end of the mechanical interference experiment (mean \pm standard deviation). Treatments: open boxes $=$ control without a grazer (control); dashed boxes=grazer present since the $6^{\text {th }}$ day (D-6); filled boxes=grazer present since the start of the experiment (D-12). The same letters above the bars indicate that the values do not differ significantly (Tukey, $\mathrm{P}<0.05$ ). 
is consistent with the findings of Oberhaus et al. (2007), who reported that $D$. pulicaria grazed preferentially on filaments of $P$. rubescens that were shorter than $100 \mu \mathrm{m}$. However, the mechanical interference was not the only factor causing shorter filaments in our experiments. Although to a lesser extent, shorter filaments were also observed when daphnids were placed in cages to exclude grazing (Fig. 2A). Shortening could be a result of reduced growth under P-limitation. Such limitation in the presence of Daphnia was observed by Paterson et al. (2002). They suggested that $\mathrm{P}$ excreted by daphnids is less available for uptake by phytoplankton. The suppression of growth of some Microcystis strains by Daphnia infochemicals was also observed (van Gremberghe et al., 2009). It is worth noting that the mechanical disturbance caused by stirring in Aphanizomenon cultures during the experiment can be excluded as a cause of shortening because it was ruled out in the procedural control experiment. The changes in the width of filaments were also observed in both experiments. Thicker filaments were noted both in the treatments that had the direct pressure of grazers (Fig. 1B) and in the treatments in which grazing was excluded (Fig. 2B).

Considering the filament length alone, one can assume a negative influence of Daphnia on Aphanizomenon by both physical and chemical mechanisms. However, when considering the length and width of filaments together, we note in both experiments that trychomes became thicker and shorter simultaneously after 12 days of exposure. We speculate that the thickening and shortening of Aphanizomenon filaments help individuals to avoid mechanical destruction. Bednarska and Dawidowicz (2007) observed in Daphnia a reduction in intersetal and intersetular distances in the filtering apparatus to reduce the interference from filamentous cyanobacteria. The shortening and thickening of a filament may make it easier to pass through the filtering chamber without being destroyed or eaten. The ability of Daphnia to collect food particles is determined by the Reynolds number (Re). At low Re, viscous forces dominate the flow, filtering appendages act as paddles (Abrusan, 2004), and the majority of water with suspended particles (including cyanobacterial filaments) flows tangentially to the surface of filter screens (Gerrit-

\section{A}
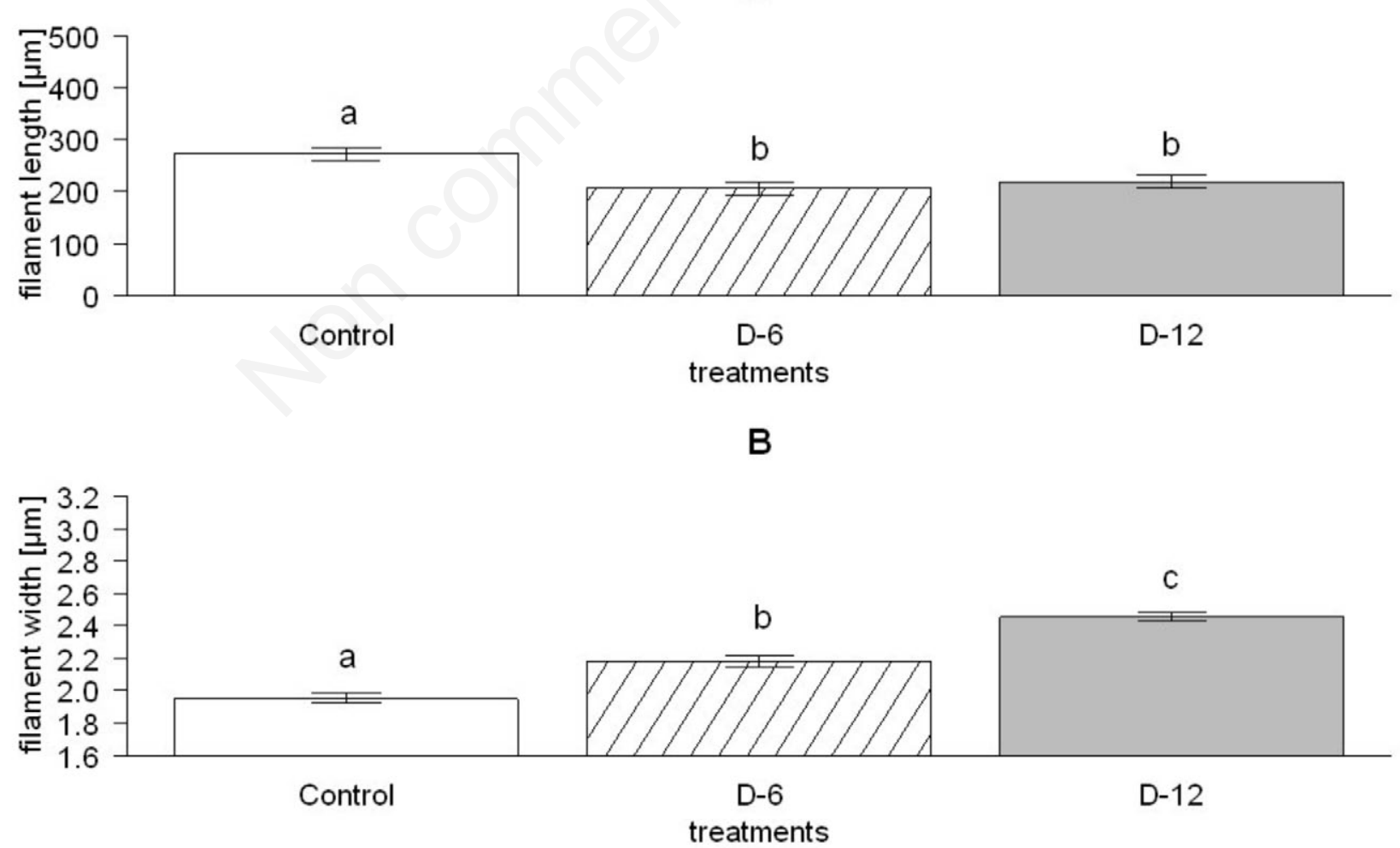

Fig. 2. Differences of Aphanizomenon's filaments in (A) length and (B) width at the end of the the experiment with Daphnia's infochemicals only (mean \pm standard deviation). Treatments: open boxes $=$ control without grazer (control); dashed boxes=grazer presence since the $6^{\text {th }}$ day (D-6); filled boxes=grazer presence since the start of the experiment (D-12). The same letters above the bars indicate that the values do not differ significantly (Tukey, $\mathrm{P}<0.05$ ). 
sen et al., 1988). In such conditions, food gathering is predominantly based on direct interception (adhesion) rather than filtration (Rubenstein and Koehl, 1977; Koehl, 1996). The width of filaments is particularly important in light of the results of Nadin-Hurley and Duncan (1976), who reported that a limiting factor for ingestion was the width, rather than the length, of a particle, and most of very large particles found in the daphnid's gut were long, narrow, pliant filaments, such as those of Tribonema. However, long filaments of cyanobacteria inside the filtering apparatus of Daphnia can tangle and form irregular complexes (Hartmann and Kunkel, 1991). In this form, the filamentous cyanobacteria cannot be eaten; in fact, the postabdominal rejection movements can tear and break them. It seems reasonable that reducing mechanical interference is convenient for both Daphnia and Aphanizomenon. Daphnia can filter more efficiently without rejecting food particles, while avoiding destruction is advantageous to cyanobacteria. Unfortunately, we do not have data concerning the differences in the grazing efficiency of Daphnia that are fed with two morphological forms of filaments.

Another explanation for our findings could be related to nutrients. It is highly possible that thicker filaments allow cyanobacteria to store more nutrients per unit of length than thinner ones. Moreover, thicker filaments have a larger area that can be used for nutrient intake when in contact with Daphnia. This possibility is predicted by mathematical models (Ramin et al., 2012), and Doblin et al. (2012) reported that Cylindrospermopsis is subsidised by nutrients that are recycled by zooplankton and, thus, obtains a competitive advantage over other phytoplankton species. The nutrient hypothesis is at least partly supported by the results from the infochemical experiment that excluded mechanical interference - in which the filaments grow wider when they are exposed to Daphnia chemicals for a longer time (D-6 vs D-12) (Fig. 2). This result is consistent with the findings of Hašler and Pouličkova (2003), who related the increase in width of trichomes in P. agardhii with the highest concentrations of P during their experiments. Additionally, Laamanen et al. (2001) demonstrated that the same strains of Nodularia express different cell dimensions when grown under different chemical or physical conditions.

\section{CONCLUSIONS}

Our experiments confirm that the changes in morphology of filaments are the reaction to the presence of a grazer such as Daphnia, which could be at least partly responsible for changes in width observed in the field. However, the results revealed more complicated interactions than we suspected. Daphnia has a negative mechanical influence on filamentous Aphanizomenon, but the presence of infochemicals alone also causes the decresase in length and increase in width. Decrease in length of filaments, despite the mechanical interference, could be also explained by nitrogen (N) excreted by daphnids and less available $\mathrm{P}$ for uptake by phytoplankton which increases the N:P ratio (Paterson et al., 2002). Such conditions are not preferable for most of cyanobacteria. The strategy of switching their growing mode and invest more heavily in width than in length is perplexing. It can either allow Aphanizomenon to withstand grazer's pressure during early stages of a bloom or be a response to the reduction of nutrient availability due to the presence of Daphnia infochemicals. Further studies are needed to determine the role of nutrient levels in changing the life history of cyanobacteria in the presence of Daphnia and to compare the resistance of thick and narrow filaments to the pressure of a grazer.

\section{ACKNOWLEDGMENTS}

We thank Maciej Bartosiewicz and Jakub Kosicki for their criticism and valuable comments on the manuscript. We would also like to thank the two anonymous reviewers whose comments and doubts greatly improved the manuscript. The financial support was provided by the National Science Centre through research grant No. NN 304014 539. The purchase and maintenance of phytoplankton cultures was financed from the Marie-Curie Reintegration Grant Contrastress No. PERG05-GA-2009249273.

\section{REFERENCES}

Abrusan G, 2004. Filamentous cyanobacteria, temperature and Daphnia growth: the role of fluid mechanics. Oecologia 141:395-401.

Bednarska A, Dawidowicz P, 2007. Change in filter-screen morphology and depth selection: Uncoupled responses of Daphnia to the presence of filamentous cyanobacteria. Limnol. Oceanogr. 52:2358-2363.

Burns CW, 1968. Direct observation of mechanisms regulating feeding behawior of Daphnia in lakewater. Int. Rev. Ges. Hydrobio. 53:83-100.

Chen F, Gulati RD, Li J, Zhengwen L, 2011. A comparison of the size distribution of the filamentous green alga Ulothrix in Daphnia guts and lake water from Lake Taihu, China. J. Plankton Res. 33:1274-1283.

Dawidowicz P, 1990. The effect of Daphnia on filament length of blue-green algae. Hydrobiologia 191:265-268.

Doblin M, Hong Y, Burford M, 2012. Nutrient recycling by herbivorous zooplankton promotes growth of the cyanobacterium Cylindrospermopsis raciborskii, p. 24. In: Abstract book of the $15^{\text {th }}$ International Conference on Harmful Algae (Korea, 28.10-02.11.2012, Changwon).

Fijałkowska E, Pajdak-Stós A, 1997. Inducible defence against a ciliate grazer Pseudomicrothorax dubius, in two strains of Phormidium (cyanobacteria). Proc. Biol. Sci. 264:937-941.

Gerritsen J, Porter KG, Strickler JR, 1988. Not by sieving alone: observations of suspension feeding in Daphnia. B. Mar. Sci. 43:366-376. 
Gliwicz ZM, Siedlar E, 1980. Food size limitation and algae interfering with food collection in Daphnia. Arch. Hydrobiol. 88:155-177.

Gonzalez FT, 1981. Studies of Oscillatoriaceae. An analysis of the Prolificae-section. Nova Hedwigia 35:167-190.

Guillard RRL, Lorenzen CJ, 1972. Yellow-green algae with chlorophyllide c. J. Phycol. 8:10-14.

Hartmann HJ, Kunkel DD, 1991. Mechanisms of food selection in Daphnia. Hydrobiologia 225:129-154.

Hašler P, Pouličkova A, 2003. Diurnal changes in vertical distribution and morphology of a natural population of Planktothrix agardhii (Gom.) Anagnostidis et Komarek (Cyanobacteria). Hydrobiologia 506:195-201.

Hessen DO, Van Donk E, 1993. Morphological changes in Scenedesmus induced by substances released from Daphnia. Arch. Hydrobiol. 127:129-140.

Jakobsen HH, Tang KW, 2002. Effects of protozoan grazing on colony formation in Phaeocystis globosa (Prymnesiophyceae) and the potential costs and benefits. Aquat. Microb. Ecol. 27:261-273.

Jang MH, Ha K, Joo GJ, Takamura N, 2003. Toxin production of cyanobacteria is increased by exposure to zooplankton. Freshwater Biol. 48:1540-1550.

Jang MH, Jung JM, Takamura N, 2007. Changes in microcystin production in cyanobacteria exposed to zooplankton at different population densities and infochemical concentrations. Limnol. Oceanogr. 52:1454-1466.

Koehl MAR, 1996. Small-scale fluid dynamics of olfactory antennae. Mar. Freshw. Behav. Phy. 27:127-141.

Kokociński M, Stefaniak K, Mankiewicz-Boczek J, Izydorczyk K, Soininen J. 2010. The ecology of the invasive cyanobacterium Cylindrospermopsis raciborskii (Nostocales, Cyanophyta) in two hypereutrophic lakes dominated by Planktothrix agardhii (Oscillatoriales, Cyanophyta). Eur. J. Phycol. 45:365-374.

Kurmayer R, 2001. Competitive ability of Daphnia under dominance of non-toxic filamentous cyanobacteria. Hydrobiologia 442:279-289.

Laamanen MJ, Gugger MF, Lehtimaki JM, Haukka K, Sivonen K, 2001. Diversity of toxic and non-toxic Nodularia isolates (Cyanobacteria) and filaments from the Baltic Sea. Appl. Environ. Microb. 67:4638-4647.

Latta LC, O’Donnell RP, Pfrender ME, 2009. Vertical distribution of Chlamydomonas changes in response to grazer and predator kairomones. Oikos 118:853-858.

Luo W, Pflugmacher S, Pröschold T, Walz N, Krienitz L, 2006. Genotype versus phenotype variability in Chlorella and Micractinium (Chlorophyta, Trebouxiophyceae). Protist 157:315-333.

Lürling M, Van Donk E, 1996. Zooplankton-induced unicellcolony transformation in Scenedesmus acutus and its effect on growth of herbivore Daphnia. Oecologia 108:432-437.

Lynch M, Shapiro J, 1981. Predation, enrichment, and phyto- plankton community structure. Limnol. Oceanogr. 26:86-102.

Nadin-Hurley CM, Duncan A, 1976. A comparison of daphnid gut particles with the sestonic particles present in two Thames Valley reservoirs throughout 1970 and 1971. Freshwater Biol. 6:109-123.

Oberhaus L, Gelinas M, Pinel-Alloul B, Ghadouani A, Humbert JF, 2007. Grazing of two toxic Planktothrix species by Daphnia pulicaria: potential for bloom control and transfer of microcystins. J. Plankton Res. 29:827-838.

Pajdak-Stós A, Fijałkowska E, Fyda J, 2001. Phormidium autumnale (Cyanobacteria) defense against three ciliate grazer species. Aquat. Microb. Ecol. 23:237-244.

Paterson MJ, Findlay DL, Salki AG, Hendzel LL, Hesslein RH, 2002. The effects of Daphnia on nutrient stoichiometry and filamentous cyanobacteria: a mesocosm experiment in a eutrophic lake. Freshwater Biol. 47:1217-1233.

Pondaven P, Gallinari M, Chollet S, Bucciarelli E, Sarthou G, Schultes S, Jean F, 2007. Grazing-induced changes in cell wall silicification in a marine diatom. Protist 158:21-28.

Pouličkova A, Hašler P, Kitner M, 2004. Annual cycle of Planktothrix agardhii (Gom.) Anagn. \& Kom. Nature population. Int. Rev. Hydrobiol. 89:278-288.

Ramin M, Perhar G, Shimoda Y, Arhonditsis GB, 2012. Examination of the effects of nutrient regeneration mechanisms on plankton dynamics using aquatic biogeochemical modeling. Ecol. Model. 240:139-155.

Romo S, 1994. Seasonal variation in size of the cyanophytes Planktothrix agardhii, Pseudoanabaena galeata and Geitlerinema sp. Verh. Int. Verein. Limnol. 25:2221-2225.

Rubenstein DI, Koehl MAR, 1977. The mechanisms of filter feeding: some theoretical considerations. Am. Nat. 111:981984.

Tollrian R, 1995. Predator-induced morphological defenses: costs, life history shifts, and maternal effects in Daphnia pulex. Ecology 76:1691-1705.

Toth GB, Noren F, Selander E, Pavia H, 2004. Marine dinoflagellates show induced life-history shifts to escape parasite infection in response to water-borne signals. Proc. Biol. Sci. 271:733-738.

Underwood AJ, 1997. Experiments in ecology. Their logical design and interpretation using analysis of variance. Cambridge University Press, Cambridge: 194 pp.

Van Donk E, Ianora A, Vos M, 2011. Induced defences in marine and freshwater phytoplankton: a review. Hydrobiologia 668:3-19.

Van Gremberghe I, Vanormelingen P, Gucht K, Mancheva A, D'hondt S, De Meester L, Vyverman W. 2009. Influence of Daphnia infochemicals on functional traits of Microcystis strains (Cyanobacteria). Hydrobiologia 635:147-155.

Von Elert E, Creuzburg MD, Le Coz JR, 2003. Absence of sterols constrains carbon transfer between cyanobacteria and a freshwater herbivore (Daphnia galeata). Proc. Biol. Sci. 270:1209-1214. 